\title{
Plano de Gerenciamento de Resíduos Sólidos do Polo Comercial de Caruaru - Pernambuco
}

\author{
Karla Giselle Silva de CASTRO
}

Universidade Federal de Pernambuco (UFPE), Recife, PE, Brasil

\section{Jaqueline Guimarães SANTOS}

Universidade Federal de Pernambuco (UFPE), Recife, PE, Brasil

\section{Pamela Karolina DIAS}

Universidade Federal de Pernambuco (UFPE), Recife, PE, Brasil

\author{
Received 17 set. 17; Accepted 12 nov. 17 \\ Evaluation System: Guest Article
}

Editor: Jose Lindenberg Julião Xavier Filho, Dr.

ISSN: 2594-8040

To cite this paper: Castro, K. G. S., Santos, J. G., \& Dias, P. K. (2017). Plano de Gerenciamento de Resíduos Sólidos do Polo Comercial de Caruaru - Pernambuco. Journal of Perspectives in Management - JPM, 1(1), p. 51-62.

\section{Resumo}

O expressivo número de resíduos sólidos gerados é um problema grave e parte desse problema se deve à falta de um gerenciamento adequado que possam minimizar os impactos ao meio ambiente. Com a implantação da Política Nacional de Resíduos Sólidos, foram definidas diretrizes para o governo, empresas e sociedade civil sobre a necessidade do correto gerenciamento e manejo de resíduos sólidos gerados. Assim sendo, este estudo teve como objetivo analisar como o Polo Caruaru realiza a gestão dos resíduos sólidos gerados a partir de suas atividades. No que concerne os procedimentos metodológicos, este estudo tem uma abordagem qualitativa, sendo a coleta de dados realizada por meio de entrevistas semiestruturas e observações diretas participantes, além da análise documental. Os principais resultados da pesquisa apontam que o Polo Caruaru atende algumas exigências da Política Nacional de Resíduos Sólidos, no entanto algumas práticas devem ser estabelecidas objetivando o gerenciamento correto dos resíduos sólidos gerados pelo empreendimento.

Palavras-Chave: Resíduos Sólidos, Coleta Seletiva, Polo Caruaru. 


\section{Introdução}

No contexto brasileiro, o processo de urbanização das grandes e médias cidades tem causado grandes questionamentos sobre a maneira mais eficaz de gerenciar os resíduos sólidos gerados pela população. O impacto ambiental causado pela disposição inadequada dos resíduos no meio ambiente resulta em fatores negativos restritivos para o desenvolvimento de uma região, pois reduzem a qualidade de vida e tem efeitos negativos sobre a saúde, economia e diversas áreas (Marsaro, 2009).

Para Besen, Günther, Rodriguez e Brasil (2010) a gestão e a disposição inadequada dos resíduos sólidos causam impactos socioambientais, tais como degradação do solo, comprometimento dos corpos d'água e mananciais, intensificação de enchentes, contribuição para a poluição do ar e proliferação de vetores de doenças. Segundo a Associação Brasileira de Empresas de Limpeza Pública e Resíduos Especiais (Abrelpe) "a geração de RSU revelam um total anual de 79,9 milhões de toneladas no país, configurando um crescimento a um índice inferior ao registrado em anos anterior" (Abrelpe, 2015, p.18). Ainda com base nos dados da ABRELPE "a população brasileira apresentou um crescimento de $0,8 \%$ entre 2014 e 2015 e a geração per capita de RSU cresceu no mesmo ritmo. A geração total, por sua vez, atingiu o equivalente a $218.874 \mathrm{t} / \mathrm{dia}$ de RSU gerado no país, um crescimento de $1,7 \%$ em relação ao ano anterior" (Abrelpe, 2015, p.19).

Devido à grande quantidade de resíduos gerados, a gestão integrada de resíduos sólidos deve incluir à busca por melhores condições para a gestão mais eficiente dos resíduos sólidos, os planos estão sob responsabilidade das entidades federais, estaduais e municipais (Ministério do Meio Ambiente, 2015). Segundo o Ministério do Meio Ambiente, a lei federal 12.305 de 02 de agosto de 2010 entrou em vigor a partir do dia 01 de agosto de 2014 e obriga todas as atividades comerciais e industriais a fazerem a gestão de todos os seus resíduos sólidos gerados sob pena de receberem suas licenças ambientais.

A Política Nacional de Resíduos Sólidos (PNRS) foi sancionada com os objetivos da proteção da saúde pública e da qualidade ambiental, em busca da redução, reutilização e tratamento dos resíduos sólidos, a disposição final ambientalmente adequada dos rejeitos, bem como a adoção de padrões sustentáveis de produção e consumo de bens e serviços. Além disso, a lei ainda prevê a gestão integrada de resíduos sólidos, articulação entre as diferentes esferas do poder público, e destas com o setor empresarial, integração dos catadores de materiais reutilizáveis e recicláveis nas ações que envolvam a responsabilidade compartilhada pelo ciclo de vida dos produtos, incentivo ao desenvolvimento de sistemas de gestão ambiental e empresarial voltados para a melhoria dos processos produtivos e ao reaproveitamento dos resíduos sólidos, incluídos a recuperação e o aproveitamento energético, entre outras iniciativas (Política Nacional de Resíduos Sólidos, 2012).

A PNRS integra a política nacional do meio ambiente e articula-se com a política nacional de educação ambiental e com a política de saneamento básico propondo a gestão integrada dos resíduos sólidos. Os objetivos propostos ao setor público, bem como ao setor privado e a sociedade civil são desafiantes, não só em razão da demora pela edição da lei e adoção de uma política específica para a questão dos resíduos sólidos, mas também pela necessidade de articulação entre diferentes políticas estatais (Albuquerque \& Medeiros, 2016).

Para as empresas o gerenciamento correto de resíduos sólidos gerados por suas atividades é um fator importante para que estas possam minimizar seus impactos ao meio ambiente e contribuírem para a sustentabilidade local. É cada vez mais evidente que o gerenciamento adequado dos resíduos sólidos pode reduzir significativamente os impactos ao ambiente e à saúde humana (Besen, et al., 2010).

Assim, o gerenciamento de resíduos sólidos torna-se uma poderosa ferramenta para utilização de princípios para a preservação do meio ambiente, pois engloba o processo de sistematização das técnicas de redução, reciclagem e reutilização e abrange medidas adequadas desde a geração e acondicionamento até sua disposição final (Marsaro, 2009). Tal gerenciamento torna-se importante para todas as empresas, tanto para gestão e manejo dos resíduos gerados em seus processos produtivos, como também em suas atividades gerais.

Quando se trata de shoppings centers o número de resíduos gerados é enorme, visto que reúnem várias lojas e suas atividades são responsáveis pela geração de grandes quantidades de resíduos que contribuem diretamente para a poluição urbana (Sforni, Oiko, Moretti, \& Culchesk, 2011). Assim, considerando a importância de as empresas gerenciarem eficientemente os resíduos sólidos gerados por estas, este estudo foi realizado em um shopping localizado em Caruaru, Pernambuco, o qual possui um grande fluxo de pessoas circulando em seus módulos e na praça de alimentação diariamente, gerando uma grande quantidade de resíduos sólidos (Polo Caruaru, 2017). 
Deste modo, este estudo tem por objetivo analisar como o Polo Caruaru realiza o gerenciamento dos resíduos sólidos gerados a partir de suas atividades. No que concerne os procedimentos metodológicos, este estudo tem uma abordagem qualitativa, sendo a coleta de dados realizada por meio de entrevistas semiestruturas, observações diretas participantes, além da análise documental. Este estudo está estruturado em cinco seções, além desta introdutória, tem-se a revisão de literatura a seguir, logo após o método da pesquisa, em seguida os resultados do estudo e, por fim as considerações finais.

\section{Revisão da Literatura}

Para a construção da pesquisa foi elaborada uma revisão da literatura sobre os principais temas e seus respectivos teóricos que embasaram o estudo. Assim sendo, inicialmente é abordado sobre a gestão socioambiental das empresas, logo após gerenciamento de resíduos sólidos e, por fim, será apresentado a Política Nacional de Resíduos Sólidos.

\subsection{Gestão Socioambiental das Empresas}

Uma forma das empresas minimizarem seus impactos ao meio ambiente e a sociedade se dar por meio da gestão voltada a sustentabilidade. Segundo Dias (2000), o desenvolvimento econômico, o desenvolvimento social e cultural e a preservação ambiental devem ser realizados simultaneamente e em harmonia pelas empresas. Assim, para que um empreendimento ser considerado sustentável, é preciso levar em consideração se ele é ecologicamente correto, economicamente viável e socialmente justo, de modo que todas as atividades precisam ser monitoradas a fim de perceber a sua evolução com o passar dos anos (Silva, 2011).

Para Oliveira Filho (2004) a empresa que trabalha com a gestão ambiental se antecipa aos concorrentes ao ver o meio ambiente como oportunidade. A gestão ambiental é vista de maneira sistêmica, holística e como solucionador dos problemas ambientais da organização. Dentre as ações de gestão ambiental, destacamos neste estudo aquelas relacionadas a gestão de resíduos sólidos gerados pelas organizações.

Nesse sentido, Besen et al. (2010) afirmam que o gerenciamento adequado dos resíduos sólidos pode reduzir significativamente os impactos ao ambiente e à saúde humana. O gerenciamento torna-se uma poderosa ferramenta para utilização de princípios para a preservação do meio ambiente, pois engloba o processo de sistematização das técnicas de redução, reciclagem e reutilização e abrange medidas adequadas desde a geração e acondicionamento até sua disposição final (Marsaro, 2009).

Assim, o gerenciamento de resíduos sólidos é um fator importante para que as empresas possam minimizar seus impactos e contribuírem para a sustentabilidade local (Barbieri \& Cajazeira, 2009). Usar da criatividade e das condições internas, podem se considerar, a reciclagem de materiais como uma das oportunidades para empresas e que essa prática traz grande economia de recursos por meio do reaproveitamento interno de resíduos ou até mesmo a venda deste material para outras empresas (Donaire, 1995).

Considerando a importância de as empresas realizarem a gestão eficiente dos resíduos sólidos gerados em suas atividades, a partir das práticas de gestão ambiental empresarial, a seção seguinte aborda a importância das práticas para o gerenciamento dos resíduos sólidos, como a reciclagem e coleta seletiva.

\subsection{Gerenciamento de Resíduos Sólidos: Uma prática emergente}

O modo de vida urbano produz resíduos em quantidade e diversidade cada vez maiores, exigindo sistemas de coleta, tratamento pós-consumo e uma destinação ambientalmente segura, haja vista que existem inúmeros fatores de risco à saúde humana, da geração até a disposição final (Silva, 2011). Sabemos que os resíduos sólidos possuem várias denominações, origens diferenciadas e diversas composições. Com isso a gestão dessa variedade de resíduos tem responsabilidade definidas em legislações específicas e implica sistemas diferenciados de coleta, tratamento e disposição final (Besen, et al., 2010).

O problema relacionado a falta de gestão dos resíduos sólidos ${ }^{1}$ é agravada pelo fato de que a maior parte desses resíduos é disposta inadequadamente em lixões a céu aberto ou em aterros que atendem parcialmente às normas de engenharia sanitária e

\footnotetext{
${ }^{1}$ De acordo com a ABNT (2012), resíduos sólidos são resíduos nos estados sólido e semissólido, que resultam de atividades de origem industrial, doméstica, comercial, hospitalar, agrícola, de serviços e de varrição, ficam incluídos nesta definição os lodos provenientes de sistemas de tratamento de água e instalações de controle de poluição, bem como alguns líquidos cujas particularidades tornam inviável o seu lançamento na rede pública de esgotos ou corpos de água, ou exijam para isso soluções técnica e economicamente inviáveis em face à melhor tecnologia disponível.
} 
ambiental, causando a poluição do ar, da água e do solo, com sérios impactos sobre a saúde das populações. Santos (2011) sugere que uma das formas de amenizar o problema é por meio da reciclagem de materiais.

A reciclagem se define como o processo de reaproveitamento dos resíduos sólidos, no qual seus componentes são separados, transformados e recuperados, economizando matéria-prima e energia, combatendo o desperdício, reduzindo a poluição ambiental e valorizando os resíduos, e mudando a concepção em relação aos mesmos (Programa das Nações Unidas para o Desenvolvimento, 1998). Sendo assim, Seiffert (2011) argumenta que o processo de reciclagem apresenta vantagens sobre os processos de obtenção e extração de matéria prima virgem, por meio do processo de recuperação de materiais.

Gonçalves (2003) classifica os processos da reciclagem em três etapas: recuperação, que engloba os processos de separação do resíduo na fonte, coleta seletiva, prensagem, enfardamento; revalorização, que compreende os processos de beneficiamento dos materiais, como a moagem e a extrusão e, por fim, a transformação; que é a reciclagem propriamente dita, transformando os materiais recuperados e revalorizados em um novo produto.

Já a coleta seletiva consiste na separação de materiais recicláveis, como plásticos, vidros, papéis, metais, entre outros, nas várias fontes geradoras residências, empresas, escolas, comércio, indústrias. Esses materiais representam cerca de $30 \%$ da composição do lixo domiciliar brasileiro, que na sua maior parte é composto por matéria orgânica. A separação dos materiais recicláveis cumpre um papel estratégico na gestão integrada de resíduos sólidos sob vários aspectos, quais sejam: 1. Estimula o hábito da separação do lixo na fonte geradora para o seu aproveitamento; 2. Promove a educação ambiental voltada para reduzir o consumo e o desperdício e 3. Gera trabalho, renda para cooperativas de catadores (Santos, 2011).

Contudo, compreende-se que as práticas de descarte e reciclagem são pouco expressivas, porque é um tipo de ação onde o ganho financeiro é pouco percebido. Por isso, é importante os diferentes grupos da sociedade trabalharem incentivando ou mesmo obrigando que as empresas tenham programas de reciclagem ou de descarte corretos de seus produtos e resíduos que não tenham destino ou uso (Lunardi, Frio \& Brum, 2011).

Diante da necessidade de gerenciar os resíduos sólidos, tendo em vista, que cada vez mais pelo consumismo, mais resíduos estão sendo gerados, foi elabora uma legislação para dar suporte, a Política
Nacional de Resíduos Sólidos, que abrange todo o país, com diretrizes e orientações a serem adotadas. Na próxima seção será tratado os principais aspectos da política.

\subsection{Política Nacional de Resíduos Sólidos - PNRS}

Para Barbieri (2007), o surgimento de leis sobre a gestão ambiental pública, parte da necessidade de políticas para regular as atividades que causem danos ao ambiente, evitando ou minimizando os impactos. A aplicabilidade dessas legislações é por meio do poder público, que se baseia em políticas públicas ambientais.

A crescente preocupação com a preservação dos recursos naturais e com a questão de saúde pública associada a resíduos sólidos indica que as políticas públicas para tratar desses temas tendem a ser cada vez mais demandadas pela sociedade. Reflexo exatamente dessas demandas, foi sancionada em agosto e regulamentada em dezembro de 2010 a Política Nacional de Resíduos Sólidos, que reúne o conjunto de diretrizes e ações a ser adotado com vistas à gestão integrada e ao gerenciamento adequado dos resíduos sólidos (PNRS, 2012).

De acordo com a Lei 12.305 de agosto de 2010, a PNRS reúne o conjunto de princípios, objetivos, instrumentos, diretrizes, metas e ações adotados pelo governo federal, isoladamente ou em regime de cooperação com estados, distrito federal, municípios ou particulares, com vistas à gestão integrada e ao gerenciamento ambientalmente adequado dos resíduos sólidos. A PNRS integra a Política Nacional do Meio Ambiente e articula-se com a Política Nacional de Educação Ambiental, regulada pela Lei $\mathrm{n}^{\circ}$ 9.795, de 27 de abril de 1999, com a Política Federal de Saneamento Básico, regulada pela Lei $\mathrm{n}^{\mathrm{o}} 11.445$, de 2007, e com a Lei $\mathrm{n}^{\circ} 11.107$, de 6 de abril de 2005 .

Dentre os objetivos da PNRS alguns deles são: a proteção da saúde pública e da qualidade ambiental; a não geração, redução, reutilização, reciclagem e tratamento dos resíduos sólidos, bem como disposição final ambientalmente adequada dos rejeitos; Estimular à adoção de padrões sustentáveis de produção e consumo de bens e serviços; a adoção, desenvolvimento e aprimoramento de tecnologias limpas como forma de minimizar impactos ambientais, redução do volume e da periculosidade dos resíduos perigosos; gestão integrada de resíduos sólidos; e articulação entre as diferentes esferas do poder público, e destas com o setor empresarial, com vistas à cooperação técnica e 
financeira para a gestão integrada de resíduos sólidos. Integração dos catadores de materiais reutilizáveis e recicláveis nas ações que envolvam a responsabilidade compartilhada pelo ciclo de vida dos produtos (PNRS, 2012).

Considerando a crescente preocupação da sociedade com relação às questões ambientais e ao desenvolvimento sustentável, a Associação Brasileira de Normas Técnicas criou a Comissão de Estudo Especial Temporária de Resíduos Sólidos (CEET-00.01.34) para revisar a ABNT NBR 10004:1987 - Resíduos sólidos - Classificação, visando a aperfeiçoá-la e, que é a norma referente aos resíduos sólidos, a fim de melhoria da norma e fornecer subsídios para o gerenciamento de resíduos sólidos (Associação Brasileira de Normas Técnicas, 2004).

A associação brasileira de normas técnicas (2004) classifica os resíduos sólidos em duas classes: Classe I ou Perigosos e Classe II ou Não Perigosos. Os resíduos sólidos perigosos são aqueles que, em função de suas propriedades físicas, químicas ou biológicas, podem apresentar riscos à saúde e ao meio ambiente. Possuem uma ou mais das seguintes propriedades: inflamabilidade, corrosividade, reatividade, toxidade e patogenecidade. Ainda segundo a ABNT os resíduos sólidos não perigosos são subdivididos em duas classes: classe II-A e classe II-B. A classe II-A - não inertes podem ter as seguintes propriedades: biodegradabilidade, combustibilidade ou solubilidade em água. Os resíduos classe II-B inertes não apresentam nenhum de seus constituintes solubilizados a concentrações superiores aos padrões de potabilidade de água, com exceção dos aspectos cor, turbidez, dureza e sabor.

Diante da revisão de literatura notamos que por meio da gestão ambiental as empresas realizar efetivamente o gerenciamento de resíduos sólidos gerados em suas atividades, o que pode contribuir para minimização dos seus impactos ao meio ambiente. Para tanto, destacamos que é necessário que as organizações entendam os objetivos da PNRS e apliquem em suas práticas. A sessão a seguir apresenta os procedimentos metodológicos utilizados para realização deste estudo.

\section{Método}

Para atendimento do objetivo de analisar como o Polo Caruaru realiza o gerenciamento dos resíduos sólidos gerados a partir de suas atividades, foi realizada uma pesquisa de abordagem qualitativa. Quanto aos fins trata-se de uma pesquisa descritiva, segundo Gil (1991), a pesquisa descritiva descreve as características de determinadas populações ou fenômenos. Quanto aos meios, foi feita por meio de pesquisa de campo, segundo Vergara (2009), pesquisa de campo é investigação empírica realizada no local onde ocorre o fenômeno, que dispõe de elementos para explicá-lo.

A coleta de dados se deu por meio de entrevistas semiestruturadas realizadas com gestores do empreendimento, com base em instrumento de coleta de dados elaborado a partir da revisão de literatura apresentada na seção 2. Tal instrumento continha questões sobre a geração e o manejo dos resíduos gerados pelo shopping de compras, o Polo Caruaru. O Quadro 01 a seguir apresenta os participantes da pesquisa.

\begin{tabular}{|c|c|c|}
\hline CÓDIGO & \multicolumn{2}{|c|}{ ENTREVISTADO } \\
\hline E1 & Rodrigo José de Arruda Leal & $\begin{array}{c}\text { Perito e auditor ambiental, responsável pela implantação do } \\
\text { gerenciamento de resíduos sólidos no empreendimento. }\end{array}$ \\
\hline E2 & $\begin{array}{c}\text { Sérgio José de Albuquerque e } \\
\text { Souza Júnior }\end{array}$ & Gerente de Operações do empreendimento \\
\hline E3 & Fábio Florentino de Lima Silva & Chefe de Manutenção do Empreendimento \\
\hline E4 & Carlos Eduardo de Souza Pereira & Gerente da Asproma \\
\hline
\end{tabular}

Quadro 1: Participantes da pesquisa.

Fonte: Elaboração própria.

Além das entrevistas, foram realizadas observações participantes, uma vez que uma das pesquisadoras é colaborada da empresa estudada, lotada no setor de Recursos Humanos e Departamento Pessoal. Todas as observações foram registradas em um bloco de notas da pesquisadora, cujo foco de tais observações era identificar as formas de tratamento e manejo dos resíduos gerados no Polo Caruaru. A observação participante é uma técnica comum de pesquisa para coleta e análise de dados onde o pesquisador-observador torna-se parte integrante de uma estrutura social, e na relação face a face com os sujeitos da pesquisa realiza a coleta de dados e informações (Martins, 2010). A coleta de dados foi realizada no período de entre novembro e dezembro de 2016. 
O plano de análise dos dados foi feito através do tratamento dos dados que segundo Vergara (2009), é analisar os dados com o objetivo desejado com a coleta de dados, o tratamento e a interpretação dos dados, fazendo a relação entre os objetivos e formas de atingi-los. Para tanto, foi realizada a análise de conteúdo, que para Bardin (2011) designa um

\section{Apresentação e Análise de Resultados}

Nesta seção são apresentados e analisados os resultados da pesquisa para fins de atendimento ao objetivo proposto. Inicialmente é feita uma caracterização do objeto de pesquisa e logo em seguida os resultados do estudo.

\subsection{Caracterização do Polo de Caruaru - Pernambuco}

Fundado em 25 de novembro 2004 por um grupo de empresários da cidade de Caruaru, o Polo Caruaru está situado no $\mathrm{km} \mathrm{62}$, às margens da BR 104. O Polo Caruaru conta com uma infraestrutura de $64 \mathrm{mil} \mathrm{m}^{2}$ de área coberta. Também dispõe de dois espaços para a realização de eventos, um com $5.111 \mathrm{~m}^{2}$, outro com $660 \mathrm{~m}^{2}$. Os ambientes são cobertos e podem receber feiras, exposições, festas e eventos em geral. $\mathrm{O}$ estacionamento com seis mil vagas, praça de alimentação e caixas eletrônicos são outras características que proporcionam comodidade aos visitantes (POLO CARUARU, 2017).

Possui mais de 300 lojas dos mais variados segmentos, como vestuário, sapatos, acessórios, artigos em couro e artesanato, etc., além das lojas e boxes, o polo possui também praça de alimentação, quiosques, uma loja ancora das americanas, a Universidade de Pernambuco e a Universidade Federal de Pernambuco (curso de medicina) e a empresa Provider que presta serviço de CallCenter, empregando mais de mil pessoas. A organização possui 97 funcionários, esses funcionários são divididos nos setores: administração, estacionamento, operações (vigilantes e bombeiros conjunto de técnicas de análise das comunicações visando obter, por procedimentos sistemáticos e objetivos de descrição do conteúdo das mensagens, indicadores (quantitativos ou não) que permitam a inferência de conhecimentos relativos às condições de produção/recepção (variáveis inferidas) destas mensagens.

patrimoniais), obras, manutenção e limpeza. Este último setor sendo responsável pela coleta de resíduos sólidos (Polo Caruaru, 2017). Devido esse grande número de operações desenvolvidas no Polo Caruaru, é alto o volume de resíduos gerados, o que incide a importância do correto gerenciamento de tais resíduos, conforme é destacado na seção a seguir.

\subsection{Gestão de Resíduos Sólidos gerados no Polo Comercial}

Os resíduos gerados no empreendimento antes da implementação de algumas práticas de gestão ambiental eram dispostos em coletores sem identificação, estes distribuídos aleatoriamente nos corredores e internamente nos boxes, não eram segregados nem possuíam quaisquer processos de reciclagem ou reaproveitamento, conforme foi mencionado pelo entrevistado E2. Segundo o entrevistado E3, os resíduos são recolhidos durante todo o período de funcionamento do complexo por um funcionário destinado exclusivamente para isso, de acordo com a demanda de resíduos gerados e perante solicitação da equipe de supervisão.

Com a implantação Plano de Gerenciamento de Resíduos Sólidos, a partir do auxílio da Avanço Consultoria, a primeira providência foi separar as lixeiras em "recicláveis" e "não recicláveis" para facilitar a separação dos resíduos gerados pela organização. As imagens abaixo mostram as lixeiras que haviam antes e as novas lixeiras espalhadas pelo empreendimento. 

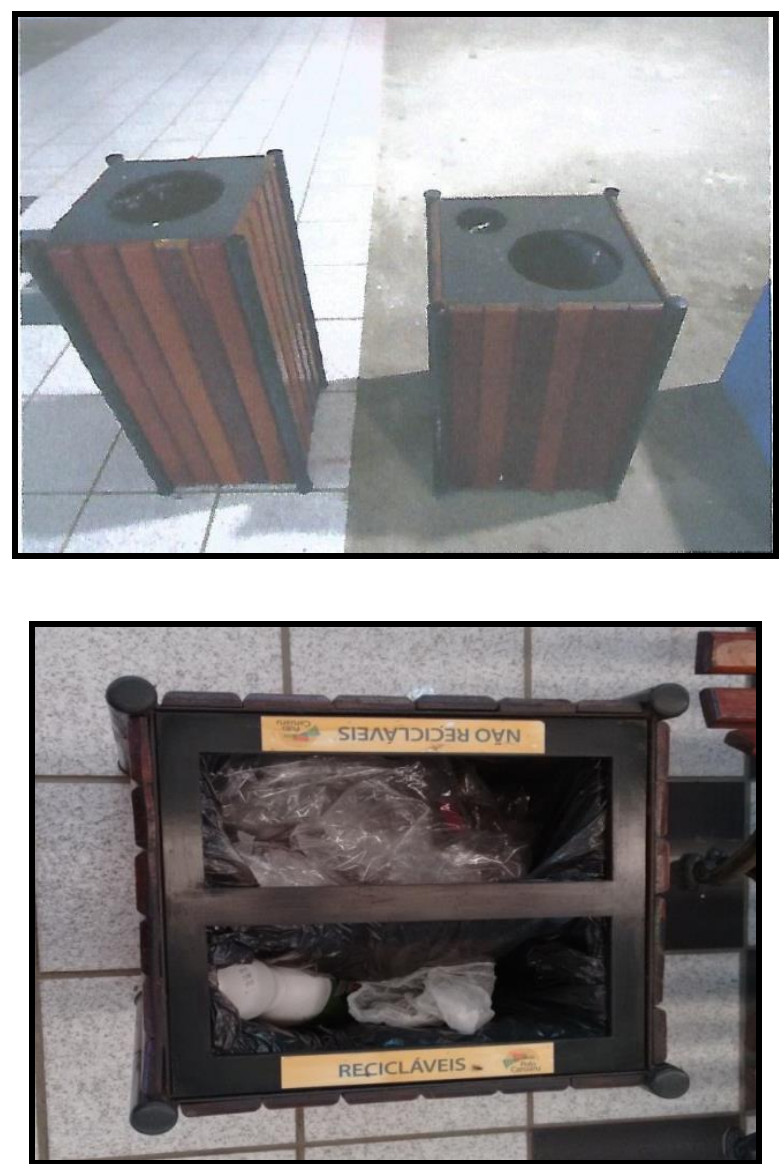

Figura 1: Lixeiras antes da implantação da PNRS $\quad$ Figura 2: Lixeira materiais recicláveis e não-recicláveis Fonte: Coleta de dados (2016)

$\mathrm{O}$ entrevistado E2 ressaltou que na seção não reciclável são colocados sacos pretos, já na seção recicláveis são colocados sacos azuis para facilitar no momento da separação dos resíduos. Uma das grandes dificuldades é a conscientização dos lojistas e clientes para dispor os resíduos no lugar correto, dificultando assim o trabalho de quem faz a coleta, pois como os resíduos não são colocados de maneira correta nas lixeiras, o coletor tem que levar todos os sacos plásticos para a central de resíduos, para então o catador separar cada resíduo, conforme afirmou o entrevistado E4.

Conforme o entrevistado E3, o empreendimento não possuía uma central de resíduos para triagem e armazenamento de maneira adequada os resíduos sólidos antes de uma destinação final. Assim, outra prática do plano de gerenciamento dos resíduos sólidos foi a construção de uma Central de Resíduos Sólidos no Polo Caruaru para melhorar a gestão de tais resíduos. Todos os dias as coletas ocorrem de 4 a 5 cinco vezes durante o dia (depende da demanda) e uma vez no turno da noite, os quais são direcionados para a central de resíduos onde um associado da Associação dos Protetores do Meio Ambiente (Asproma) realiza a seleção e tratamento dos resíduos e dar o destino correto que é para a associação. Resíduos não recicláveis, como resíduos advindos de banheiro, por exemplo, são recolhidos pela coleta de lixo urbano do município.

A Asproma é uma associação de protetores do meio ambiente que realiza a coleta de materiais na cidade de Caruaru (PE) e tem por objetivo resgatar a dignidade de quem realiza o trabalho da coleta seletiva, colaborando com a preservação ambiental e com a melhoria da qualidade de vida das pessoas. Para isso, conta com a parceria de estabelecimentos do comércio, da indústria, da rede de ensino e de outras entidades que fornecem materiais para que sejam encaminhados à reciclagem, dentre estes parceiros, destaca-se o Polo de Caruaru. A ASPROMA conta com dois núcleos de coleta seletiva, localizados nos bairros Kennedy e Salgado, em Caruaru-PE (Asproma, 2017).

Antes da implantação da central de resíduos, a empresa de coleta de lixo urbano tinha que ir ao empreendimento todos os dias fazer a coleta, depois da implantação a empresa passou a ir ao empreendimento de dois em dois dias para fazer a coleta, com exceção dos meses de Junho e Dezembro que são os meses que o empreendimento recebe um público maior, gerando assim a 
necessidade de fazer coleta mais vezes durante o dia devido ao aumento da demanda.

$\mathrm{O}$ entrevistado E3 ressaltou que a gestão dos resíduos gerados pela Loja Americanas não é de responsabilidade do Polo e sim do próprio empreendimento. No caso do grupo Provider, da Universidade Federal de Pernambuco e a Universidade de Pernambuco que tem instalações funcionando no Polo Caruaru, foram feitos acordos para que a coleta fosse feita duas vezes ao dia, porém a empresa e as instituições de ensino superior não possuem uma política de coleta seletiva, o que tem dificultado o trabalho do catador na central de resíduos, conforme ressaltado pela entrevistada E4.

\subsubsection{Tipos de Resíduos gerados no} Empreendimento quanto a sua Quantidade, Caracterização e Classificação

Conforme o entrevistado E1, antes da implantação das práticas de gestão dos resíduos sólidos não era feito nenhum procedimento para saber qual a quantidade, classificação e características dos resíduos gerados no empreendimento. Com a implantação da Lei de PNRS, foi implantado no empreendimento o Plano de Gerenciamento de Resíduos Sólidos, pois de acordo com este plano os grandes geradores de resíduos como os centros de compras, a exemplo do Polo Caruaru, teriam que aderir a Lei. A partir de outubro de 2014, a prefeitura passou a cobrar pelos resíduos que eram enviados ao aterro sanitário, gerando assim custos para o empreendimento, sendo este um fator que incentivou o Polo a aderir ao plano.

Ainda de acordo com o entrevistado E1, a partir de então, com a implantação do gerenciamento de resíduos sólidos, foi feito um levantamento para saber quais as características, classificação e quantidade de resíduos gerados, como mostra o Quadro 2 abaixo.

\begin{tabular}{|c|c|c|c|}
\hline RESÍDUOS & $\begin{array}{l}\text { LOCAL DE } \\
\text { GERAÇÃO }\end{array}$ & $\begin{array}{c}\text { CLASSIFICAÇÃO } \\
\text { ABNT }\end{array}$ & $\begin{array}{l}\text { QUANTIDADE } \\
\text { (média/mês) }\end{array}$ \\
\hline Aluminio & A, B, C e D & II A & $248,6 \mathrm{~kg}$ \\
\hline Borrachas & D & II B & $01 \mathrm{~kg}$ \\
\hline Copos plásticos & $\mathrm{A}, \mathrm{B}$ e C & II A & $385,71 \mathrm{~kg}$ \\
\hline Ferro & Be D & II A & $81,43 \mathrm{~kg}$ \\
\hline Baterias/Pilhas & $A, B$ e D & I/IIA & $0,5 \mathrm{~kg}$ \\
\hline Lâmpadas & $A, B, C$ e D & 1 & $09 \mathrm{~kg}$ \\
\hline Óleo de cozinha & $\mathrm{C}$ & II A & $129 \mathrm{~kg}$ \\
\hline Papel & A, B, C e D & II A & $287,1 \mathrm{~kg}$ \\
\hline Papelão & $A, B, C$ e D & II A & $1.221,4 \mathrm{~kg}$ \\
\hline Materiais PET & $\mathrm{A}, \mathrm{B}$ e C & $\| \mathrm{A}$ & $471,4 \mathrm{~kg}$ \\
\hline Plásticos & A, B, C e D & II A & $960 \mathrm{~kg}$ \\
\hline $\begin{array}{l}\text { Resíduos não- } \\
\text { recicláveis }\end{array}$ & $\mathrm{B}$ e $\mathrm{C}$ & II A & $\cdot 8.413 \mathrm{~kg}$ \\
\hline Sobras de alimentos & $\mathrm{C}$ & II A & $6.878,6 \mathrm{~kg}$ \\
\hline Latas de tintas* & A, B, Ce D & 1 & $04 \mathrm{~kg}$ \\
\hline Vidro & A, B, C e D & II B & $04 \mathrm{~kg}$ \\
\hline
\end{tabular}

Legenda

- Local de geração de resíduos: A- Administração; B- Área comum; C- Área de alimentação; D- Oficina Quadro 2: Tipos de Resíduos, local de geração, classificação e quantidade

Fonte: Polo Caruaru, 2016

A quantidade de resíduos gerados no empreendimento depende do mês, nos meses de maio, junho, novembro e dezembro são os meses com maior fluxo de pessoas no Polo Caruaru, consequentemente, são os meses que a quantidade de resíduos gerados aumenta significativamente. Como já mencionamos, a partir da implantação do Plano de Gerenciamento de Resíduos Sólidos, os resíduos gerados são encaminhados para central para ser separado pelo associado da ASPROMA de acordo com a classificação do material, depois é encaminhado para a associação para ter seu destino correto.

Os materiais não recicláveis vão para o aterro sanitário do município. Já os restos de material de construção são reutilizados como asfaltos no estacionamento e na entrada do próprio Polo Caruaru. Os vidros que sobram como resto de construção são guardados em local adequado, quando quebra algum vidro de outra loja, esses vidros são reutilizados, segundo o entrevistado E1. 
De acordo com o entrevistado E3, os restos orgânicos são doados para suinocultores para utilização na ração animal, são coletados duas vezes ao dia. Já os restos de óleos de cozinha dos restaurantes são colocados em tambores e encaminhados para ASA, empresa de Recife responsável pela coleta de óleos de cozinha. Nas entradas principais do Polo Caruaru também tem coletores para que os visitantes, funcionários e lojistas também depositem para serem enviados para a ASA, como mostra Figura 3 abaixo.

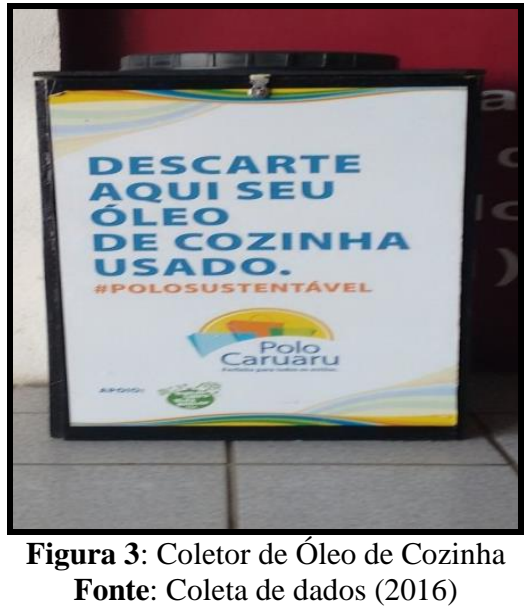

Segundo o entrevistado E2, o desenvolvimento sustentável é um dos grandes desafios para os gestores da atualidade, pois querem desenvolver sem prejudicar o meio ambiente, o plano de gerenciamento de resíduos sólidos no início foi implantado devido as leis que obrigaram as empresas a fazerem esse procedimento, porém "depois que o plano ficou pronto e começou a ser colocado em prática foi observado que os custos reduziram, pois passou a pagar menos a Locar para levar os resíduos ao aterro sanitário".

\subsection{Polo Caruaru e a Política Nacional de Resíduos Sólidos}

Segundo o entrevistado E2, o Polo Caruaru teve algumas dificuldades em seguir os objetivos da PNRS no momento da implantação do Plano de Gerenciamento de Resíduos Sólidos, no que se refere a não geração, redução e a disposição ambientalmente adequada dos rejeitos. O empreendimento não tem como ter controle dos resíduos produzidos pelos lojistas, pelas universidades e pela Provider.

$\mathrm{Na}$ parte administrativa do empreendimento foram tomadas algumas medidas, por exemplo, para reduzir a quantidade de papéis que são descartados diariamente foi solicitado que os funcionários utilizassem os versos da folha de papel, foi distribuído para todos os funcionários garrafas de água, diminuindo assim a quantidade de copos descartáveis que eram usados diariamente. Outra medida adotada foi colocar telhas brancas na praça de alimentação para aproveitamento da luz solar e minimização do consumo de energia.

Além disso, foi feito um treinamento com funcionários apresentando a importância da Implantação do Plano de Gerenciamento de Resíduos Sólidos no Polo Caruaru, explicando o que são materiais recicláveis, não recicláveis e orgânicos, coleta seletiva, etc. $\mathrm{O}$ mesmo procedimento foi feito com os lojistas, só que no caso dos lojistas os consultores iam de loja em loja, de acordo com informações passadas pelo entrevistado E2.

Com base nos resultados da pesquisa, observamos que o gerenciamento mudou a forma como os gestores lidavam com os resíduos sólidos, passando a perceber que realmente é necessário fazer a coleta, segregação e destinação correta. Ainda na visão do entrevistado E2, a parte mais importante do gerenciamento de resíduos sólidos gerados no empreendimento foi a construção da central de resíduos, "fazendo assim com que se tirasse um catador da rua e passando a trabalhar em um local seguro, com todos os equipamentos de segurança do trabalho necessário e com banheiro, acredito que isto trouxe dignidade ao catador de resíduos".

Tais resultados estão em coerência com Nascimento, Lemos, \& Mello (2008, p.209), quando estes autores afirmam que há muitas vantagens para as empresas que adotam práticas de gestão ambiental, sejam elas de pequeno, médio ou grande porte. Tais práticas podem possibilitar às 
organizações uma melhor condição de gerenciamento de seus aspectos e impactos ambientais, "além de interagir na mudança de atitudes e de cultura da organização. Pode também alavancar os seus resultados financeiros, uma vez que atua na melhoria contínua de processos e serviços".

\section{Considerações Finais}

Por meio de análise dos dados coletados desta pesquisa foi possível verificar que o empreendimento, mesmo com pouco tempo de implantação do Plano de Gerenciamento de Resíduos Sólidos, mesmo não conseguindo atender completamente os objetivos vigentes da Política Nacional de Resíduos Sólidos, procura implantar algumas práticas estabelecidas pela política e tem resultados em vantagens para a empresa.

Diante das entrevistas realizadas perceber-se que a maior dificuldade do empreendimento na implantação efetivo do plano está em conseguir que os lojistas e circulantes do Polo Caruaru descartem os resíduos gerado no lugar adequado, visto que o empreendimento possui lixeiras com lugares específicos para serem colocados os resíduos. Observou-se que é preciso que o Polo ofereça mais treinamentos com os funcionários e lojistas do Polo Caruaru, com o foco de argumentar sobre a importância da coleta seletiva, reciclagem e gerenciamento correto dos resíduos gerados pelo empreendimento.

Algumas práticas positivas realizadas pelo Polo Caruaru apontadas nesta pesquisa são: a preocupação com a destinação correta do óleo de cozinha, dos materiais recicláveis como papéis, papelão, sacos plásticos, latas e os restos orgânicos. Outro ponto positivo na pesquisa foi a relação harmoniosa com a Asproma, sendo possível um associado desenvolver suas atividades de forma adequada. Como sugestão para a empresa é a instalação de um coletor de pilhas e baterias para possibilitar que as pessoas depositem, já que é um espaço de grande circulação de pessoas.

Diante disto, é possível concluir que a implementação da PNRS trouxe benefícios para a organização no que se refere ao fato de estarem até o momento conseguindo atender algumas normas vigentes pela PNRS, porém é preciso que a organização procure outras associações para aqueles resíduos que não possuem uma destinação correta.

\section{Referências}

Albuquerque, L., \& Medeiros, F. (2016). A Política Nacional de Resíduos Sólidos e o Desenvolvimento Sustentável. Recuperado de: http://www.publicadireito.com.br/artigos/?cod=1 be9573be51135cd.

Associação Brasileira De Normas Técnicas (ABNT). (2004). Classifica os resíduos sólidos com relação aos seus potenciais riscos ao meio ambiente e à saúde pública. NBR 10.004, Rio de Janeiro.

Associação Brasileira de Normas Técnicas. (2016). Resíduos Sólidos - Classificação ABNT NBR $10004 . \quad$ Recuperado de: http://zeroacidentes.com.br/wpcontent/uploads/2014/09/NBR-10004.pdf

Associação Brasileira das Empresas de Limpeza Pública e Resíduos Especiais - ABRELPE (2017). Recuperado de http://www.abrelpe.org.br/Panorama/panorama20 15.pdf .

Albuquerque, J. L. (org.). (2009). Gestão ambiental e responsabilidade social: conceitos, ferramentas e aplicações. São Paulo: Atlas.

Associação dos Protetores do Meio Ambiente (Asproma). (2017). Sobre. Recuperado de https://asproma.wordpress.com/about/.

Barbieri, J. C. (2007). Gestão ambiental empresarial: conceitos, modelos $e$ instrumentos. 2. ed. São Paulo: Saraiva.

Barbieri, J., \& Cajazeira, J. E. R. (2009). Responsabilidade social empresarial e empresa sustentável: da teoria a pratica. São Paulo: Saraiva.

Bardin, L. (2011). Análise de conteúdo. São Paulo: Edições 70.

Besen, G. R., Günther, W. M. R., Rodriguez, A. C., \& Brasil, A. L. (2010). Resíduos sólidos: vulnerabilidades e perspectivas. In: SALDIVA P. et al. Meio Ambiente e Saúde: o desafio das metrópoles. São Paulo: Editora Ex Libris, 200 p.

Dias, G. F. (2000). Educação Ambiental: Princípios e Práticas. 6 ed. São Paulo: Gaia.

Donaire, D. (1995). Gestão ambiental na empresa. 2 ed. - 11. Reimpr. São Paulo: Atlas.

Gonçalves, P. (2003). A reciclagem integradora dos aspectos ambientais sociais e econômicos. Rio de Janeiro: DP\&A: FASE.

Lunardi, G. L., Frio, R. S., \& Brum, M. de M. (2011). Tecnologia da Informação e 
Sustentabilidade: Um estudo sobre a disseminação das práticas de TI Verde nas organizações. In: Anais do XXXV Encontro da ANPAD, Rio de Janeiro.

Martins, G. De A., \& Lintz, A. (2010). Guia para elaboração de monografias e trabalhos de conclusão de curso. 2 Ed. São Paulo: Ed. Atlas S.A.

Marsaro, G. C. S. (2009). Plano de Gerenciamento de Resíduos Sólidos de um Shopping Center de Grande Porte do Estado de Goiás. Dissertação (Pós-Graduação em Engenharia do Meio Ambiente) - Escola de Engenharia Civil da Universidade Federal de Goiás.

Ministério Do Meio Ambiente. (2016). Recuperado de: http://www.mma.gov.br.

Nascimento, L. F., Lemos, Â. D. Da C., \& Mello, M. C. A. de. (2008). Gestão socioambiental estratégica. Porto Alegre: Bookman.

Oliveira Filho, Jaime E. (2004). Gestão ambiental e sustentabilidade: um novo paradigma ecoeconômico para as organizações modernas. Revista Domus online, 1(1), p. 92-113. jan.,/jun.

Plano De Gerenciamento De Resíduos Sólidos, (2016). Documento Interno. Polo Caruaru.

Política Nacional De Resíduos Sólidos. (2012). Centro de Documentação e Informação, Edição: Câmara, Brasília.
Polo Caruaru. (2017). Recuperado de: http://polocaruarupe.com.br/lojas/.

Programa das Nações Unidas para o Desenvolvimento. (1998). Educação Ambiental na Escola e na Comunidade. Brasília: Programa das Nações Unidas para o Desenvolvimento/ONU

Santos, Z. dos. (2011). Coleta Seletiva e Responsabilidade Social: $O$ Caso da Cooperativa de Reciclagem, Trabalho e Produção - Cortrap, em Brasília. Brasília.

Seiffert, M. E. B. (2011). Gestão ambiental: instrumentos, esferas de ação e educação ambiental. 2 ed. São Paulo: Atlas.

Silva, J. (2011). Responsabilidade social $e$ sustentabilidade: o caso da Medianeira transporte Ltda de Ijuí/RS. Monografia (Curso de Administração) - Departamento de Ciências da Administração, Contábeis, Econômicas e da Comunicação da Universidade Regional do Noroeste do Estado do Rio Grande do Sul.

Sforni, R. S., Oiko, O. T., Moretti, I. C., \& Culchesk, A. S. (2011). Gestão de Resíduos: um Estudo de Caso em um Shopping Center em Maringá. Paraná.

Vergara, S. C. (2009) Projetos e Relatórios de Pesquisa em Administração. 10 $0^{\mathrm{a}}$ Edição, São Paulo, Ed. Atlas S.A.

\title{
Solid Residuals Management Plan of the Commercial Pole of Caruaru - Pernambuco
}

\begin{abstract}
The high numbers of solid waste are a serious problem, part of this problem is due to the lack of proper management that could minimize the impact on the environment. With the implementation of the National Solid Waste Policy, objectives were defined for the government, businesses and population on solid waste management. This study is an exploratory and descriptive research and aimed to analyze how the Polo Caruaru performs the management of solid waste generated from its activities. The data collection was performed through interviews with those responsible for the plans implementation and responsible for the company that carries out selective collection, as well as participant observation fieldwork. The survey results indicate that the solid waste management is critical to the enterprise meet the requirements of the National Solid Waste Policy, requiring only some adjustments to be made.
\end{abstract}

Keywords: Solid Waste, Selective Collection, Polo Caruaru. 


\section{Resumen}

El expresivo número de residuos sólidos generados es un problema grave y parte de este problema se debe a la falta de una gestión adecuada que pueda minimizar los impactos al medio ambiente. Con la implantación de la Política Nacional de Residuos Sólidos, se definieron directrices para el gobierno, empresas y sociedad civil sobre la necesidad de la correcta gestión y manejo de residuos sólidos generados. Así, este estudio tuvo como objetivo analizar cómo el Polo Caruaru realiza la gestión de los residuos sólidos generados a partir de sus actividades. En lo que concierne a los procedimientos metodológicos, este estudio tiene un abordaje cualitativo, siendo la recolección de datos realizada por medio de entrevistas semiestructuras y observaciones directas participantes, además del análisis documental. Los principales resultados de la investigación apuntan que el Polo Caruaru atiende algunas exigencias de la Política Nacional de Residuos Sólidos, sin embargo algunas prácticas deben ser establecidas objetivando la gestión correcta de los residuos sólidos generados por el emprendimiento.

Palabras Clave: Residuos Sólidos, Recolección Selectiva, Polo Caruaru.

\section{Sobre os Autores}

\section{Karla Giselle Silva de Castro}

Graduada em Administração pela Universidade Federal de Pernambuco (UFPE)

Rodovia BR-104, Km 59, s/n - Nova Caruaru - Caruaru - PE - Brasil - CEP 55002-970.

E-mail: karlagisellecastro@gmail.com

\section{Jaqueline Guimarães Santos}

Doutoranda em Administração pela Universidade Federal do Rio Grande do Sul (UFRGS)

Professora do Centro Acadêmico do Agreste (CAA), Universidade Federal de Pernambuco (UFPE)

Rodovia BR-104, Km 59, s/n - Nova Caruaru - Caruaru - PE - Brasil - CEP 55002-970.

E-mail: jsantos.adm@gmail.com

\section{Pamela Karolina Dias}

Graduada em Administração pela Universidade Federal de Pernambuco (UFPE)

Rodovia BR-104, Km 59, s/n - Nova Caruaru - Caruaru - PE - Brasil - CEP 55002-970.

E-mail: pamela_dias2009@hotmail.com 